\begin{tabular}{|c|c|c|}
\hline \multirow{3}{*}{$\begin{array}{r}\text { Case Reports in } \\
\text { Gastroenterology }\end{array}$} & \multirow{2}{*}{\multicolumn{2}{|c|}{ Case Rep Gastroenterol 2017;11:526-530 }} \\
\hline & & \\
\hline & $\begin{array}{l}\text { DOI: 10.1159/000479313 } \\
\text { Publisned online: September 13, } 2017\end{array}$ & $\begin{array}{l}\text { (c) } 2017 \text { The Author(s) } \\
\text { Published by S. Karger AG, Basel } \\
\text { www.karger.com/crg }\end{array}$ \\
\hline & \multicolumn{2}{|c|}{$\begin{array}{l}\text { This article is licensed under the Creative Commons Attribution-NonCommercial } 4.0 \\
\text { International License (CC BY-NC) (http://www.karger.com/Services/OpenAccessLicense). } \\
\text { Usage and distribution for commercial purposes requires written permission. }\end{array}$} \\
\hline
\end{tabular}

\title{
Laparoscopic Resection of a Jejunal Mesenteric Pseudocyst
}

\author{
Takumi Yamabuki $^{\text {a }}$ Masato Suzuoki ${ }^{a}$ Tsuzuku Murakami ${ }^{b}$ \\ Satoshi Hiranoc \\ ${ }^{a}$ Department of Surgery, Hakodate Red Cross Hospital, Hakodate, Japan; ${ }^{b}$ Department of \\ Gastroenterology, Hakodate Red Cross Hospital, Hakodate, Japan; ' Department of \\ Gastroenterological Surgery II, Hokkaido University Hospital, Sapporo, Japan
}

\section{Keywords}

Mesenteric pseudocyst · Laparoscopic resection · Jejunum

\begin{abstract}
An unusual case of a jejunal mesenteric pseudocyst treated by laparoscopic resection is reported. A 44-year-old woman was admitted to our hospital with intermittent upper abdominal pain and diarrhea. Physical examination revealed slight periumbilical tenderness, and no masses were palpable. Contrast-enhanced computed tomography showed a $4-\mathrm{cm}-$ sized nonenhancing high-density mass with a heterogeneous pattern on a proximal small bowel loop. Based on these findings, a gastrointestinal stromal tumor accompanied by hemorrhagic and cystic change, a mesenteric hematoma, or a desmoid tumor was diagnosed. Laparoscopy was performed to obtain an accurate diagnosis. Exploration of the abdominal cavity identified a $4-\mathrm{cm}$ mass originating from the mesentery of the jejunum. Segmental resection of the jejunum and its mesentery, including the mass, was performed. Macroscopically, the mass appeared to be a cystic mass of the jejunal mesentery. The mass within the cyst lumen consisted of white clayish material with no specific pathology. The final pathological diagnosis was a mesenteric pseudocyst. The patient had an uneventful postoperative course.

(c) 2017 The Author(s)

Published by S. Karger AG, Basel
\end{abstract}


Yamabuki et al.: Laparoscopic Resection of a Jejunal Mesenteric Pseudocyst

\section{Introduction}

A mesenteric cyst is a rare tumor that does not arise from any abdominal organ. Most often, these cysts are present in the small bowel mesentery (50-80\%); the next most common locations are in the large bowel mesentery (15-30\%) and in the retroperitoneal space (7$20 \%$ [1]. Ros et al. [2] used the term "pseudocyst" for the first time in the classification of mesenteric cysts in 1987. Mesenteric pseudocysts are devoid of specific endothelial lining and either infectious or traumatic etiology. Preoperative diagnosis of a mesenteric pseudocyst is usually difficult because of the lack of disease-specific signs. To the best of our knowledge, about 20 cases of this disease have been reported in the English literature. A patient with a jejunal mesenteric pseudocyst who underwent laparoscopic resection is presented, and the relevant literature is reviewed.

\section{Case Report}

A 44-year-old woman was admitted to our hospital with intermittent upper abdominal pain and diarrhea. She had a history of anxiety neurosis, hyperventilation syndrome, and alcoholic liver injury. Physical examination revealed slight periumbilical tenderness, and no masses were palpable. Laboratory data on admission showed: erythrocyte count $371 \times$ $10^{4} / \mathrm{mm}^{3}$ (normal 380-480), hemoglobin $14.2 \mathrm{~g} / \mathrm{dL}$ (normal 12-16), leukocyte count $3,570 / \mathrm{mm}^{3}$ (normal 4,000-9,000), platelet count $18.1 \times 10^{4} / \mathrm{mm}^{3}$ (normal 10-40), serum total protein $6.7 \mathrm{~g} / \mathrm{dL}$ (normal 6.7-8.3), total bilirubin $0.73 \mathrm{mg} / \mathrm{dL}$ (normal $0.2-1.2$ ), aspartate aminotransferase $36 \mathrm{IU} / \mathrm{L}$ (normal 12-28), alanine aminotransferase $15 \mathrm{IU} / \mathrm{L}$ (normal 8-34), alkaline phosphatase 199 IU/L (normal 115-274), lactate dehydrogenase 156 IU/L (normal 126-213), $\gamma$-glutamyltranspeptidase $102 \mathrm{IU} / \mathrm{L}$ (normal 12-48), serum amylase 44 $\mathrm{U} / \mathrm{L}$ (normal 37-125), blood urea nitrogen $11.3 \mathrm{mg} / \mathrm{dL}$ (normal 8-20), creatinine $0.5 \mathrm{mg} / \mathrm{dL}$ (normal 0.5-0.9), and C-reactive protein $0.01 \mathrm{mg} / \mathrm{dL}$ (normal 0-0.3). The serum level of the tumor marker carcinoembryonic antigen was 1.8 (normal $0-5$ ) $\mathrm{ng} / \mathrm{mL}$, and the carbohydrate antigen (CA19-9) level was 7.6 (normal 0-37) U/mL.

Contrast-enhanced computed tomography (CT) showed a 4-cm-sized nonenhancing high-density mass with a heterogeneous pattern on a proximal small bowel loop. The mass was well separated from the neighboring vessels and organs (Fig. 1). Based on these findings, a gastrointestinal stromal tumor accompanied by hemorrhagic and cystic change, a mesenteric hematoma, or a desmoid tumor was diagnosed. Laparoscopy was performed to obtain an accurate diagnosis. Exploration of the abdominal cavity identified a 4-cm mass, which originated from the mesentery of the jejunum (Fig. 2a). Segmental resection of the jejunum and its mesentery, including the mass, was performed. Macroscopically, the mass appeared to be a cystic mass of the jejunal mesentery, and it measured $41 \times 42 \mathrm{~mm}$. The mass within the cyst lumen consisted of white clayish material with no specific pathology (Fig. 2b). Culture of the cyst's contents for bacteria was negative. Histopathological examination of the resected tissues showed that the cystic wall was made up of fibrous tissue with infiltration of inflammatory cells, but neither a specific endothelial lining nor a proliferating lining was found (Fig. 3). The final pathological diagnosis was mesenteric pseudocyst. The patient had an uneventful postoperative course. 
Yamabuki et al.: Laparoscopic Resection of a Jejunal Mesenteric Pseudocyst

\section{Discussion}

Mesenteric cysts are rare intra-abdominal lesions arising with an incidence of $1 / 100,000$ admissions in adults and 1/20,000 in children [3]. Ros et al. [2] reviewed 41 cases of mesenteric and omental cysts, and proposed a histological classification correlated with radiological findings. These authors classified the cysts into 5 groups: (a) lymphangiomas, (b) enteric duplication cysts, (c) enteric cysts, (d) mesothelial cysts, and (e) nonpancreatic pseudocysts. The term "pseudocyst" was used in the classification of mesenteric cysts for the first time. Recently, a new classification of intra-abdominal cysts was proposed by de Perrot et al [4]. It is based on the histological identity of the internal epithelium and consists of 6 groups: (a) lymphatic cysts (simple cysts and lymphangiomas), (b) mesothelial cysts (simple cysts, benign mesotheliomas, malignant mesotheliomas), (c) enteric cysts (including enteric duplication), (d) urogenital cysts, (e) mature cystic teratoma (dermoid cysts), (f) pseudocysts (infectious, traumatic, and degenerative). Pseudocysts are histologically similar to pancreatic pseudocysts, which are usually surrounded by a thick fibrous wall without an inner epithelial lining [4]. According to these classifications, our patient's cyst was categorized as a pseudocyst. Most such lesions are posttraumatic or infectious, but in the present case, the patient did not have a history of abdominal trauma or abdominal inflammatory disease.

As most mesenteric cysts have no symptoms, they are frequently discovered by chance on ultrasonography or CT; it is difficult to detect them on physical examination or by hematological testing [5]. The symptoms of mesenteric cysts are usually nonspecific. Initial clinical presentations include abdominal pain (82\%), vomiting (45\%), constipation (27\%), and palpable abdominal mass (61\%) [4]. Complications such as torsion, rupture, hemorrhage, infection, and intestinal obstruction caused by these cysts have been reported [6, 7]. Sonographically, pseudocysts are hypoechoic masses that are frequently filled with echogenic debris. On CT images, they are hypodense, have thin walls, and show no postcontrast enhancement $[8,9]$. In the present case, CT showed a nonenhancing high-density mass in with a heterogeneous pattern; therefore, a gastrointestinal stromal tumor accompanied by hemorrhagic and cystic change, a mesenteric hematoma, or a desmoid tumor was diagnosed. The cyst was filled with white clayish material; the CT showed a nonenhancing high-density mass with a heterogeneous pattern. Such contents are unique in pseudocysts, which may be serous, chylous, gelatinous, sanguineous, or mixed [10].

With the exception of malignant cystic mesothelioma, all mesenteric cysts are benign, and their total excision is usually curative [4]. Sometimes, additional resection of neighboring organs is needed [11]. Recently, laparoscopic resection has replaced laparotomy because of its high success rate; in addition, laparoscopy can reduce surgery time and has a low rate of incidence of postoperative complications $[10,12,13]$. Although mesenteric pseudocysts are rare and their preoperative diagnosis is difficult because of the lack of specific signs, the disease must be considered in the differential diagnosis of intra-abdominal masses. We believe that laparoscopic resection is the preferred treatment for mesenteric cysts when the cysts are not huge in size.

\section{Statement of Ethics}

The authors have no ethical conflicts to disclose. 


\section{Case Reports in Gastroenterology}

\section{Disclosure Statement}

The authors have no funding or conflicts of interest to disclose.

\section{References}

1 Saviano MS, Fundarò S, Gelmini R, Begossi G, Perrone S, Farinetti A, Criscuolo M: Mesenteric cystic neoformations: report of two cases. Surg Today 1999;29:174-177.

-2 Ros PR, Olmsted WW, Moser RP Jr, Dachman AH, Hjermstad BH, Sobin LH: Mesenteric and omental cysts: histologic classification with imaging correlation. Radiology 1987;164:327-332.

3 Vanek VW, Phillips AK: Retroperitoneal, mesenteric, and omental cysts. Arch Surg 1984;119:838-842.

-4 de Perrot M, Bründler M, Tötsch M, Mentha G, Morel P: Mesenteric cysts. Toward less confusion? Dig Surg 2000;17:323-328.

5 Park SE, Jeon TJ, Park JY: Mesenteric pseudocyst of the transverse colon: unusual presentation of more common pathology. BMJ Case Rep DOI: 10.1136/bcr-2013-202682.

-6 Walker AR, Putnam TC: Omental, mesenteric, and retroperitoneal cysts: a clinical study of 33 new cases. Ann Surg 1973;178:13-19.

-7 Vijayaraghavan SB, Ravikumar VR, Srimathy G: Whirlpool sign in small-bowel volvulus due to a mesenteric cyst. J Ultrasound Med 2004;23:1375-1377.

8 Gallego JC, González JM, Fernández-Virgós A, del Castillo M: Retrorectal mesenteric cyst (nonpancreatic pseudocyst) in adult. Eur J Radiol 1996;23:135-137.

-9 Stoupis C, Ros PR, Abbitt PL, Burton SS, Gauger J: Bubbles in the belly: imaging of cystic mesenteric or omental masses. Radiographics 1994;14:729-737.

10 Kurnicki J, Swiątkiewicz J, Wrzesińska N, Skórski M: Laparoscopic treatment of a huge mesenteric pseudocyst - case report. Wideochir Inne Tech Maloinwazyjne 2011;6:167-172.

11 Chou YH, Tiu CM, Lui WY, Chang T: Mesenteric and omental cysts: an ultrasonographic and clinical study of 15 patients. Gastrointest Radiol 1991;16:311-314.

12 Tan JJ, Tan KK, Chew SP: Mesenteric cysts: an institution experience over 14 years and review of literature. World J Surg 2009;33:1961-1965.

13 Resta G, Tartarini D, Fabbri N, Bianchini E, Anania G: Laparoscopic resection of a jejunal mesenteric pseudocyst: case report. G Chir 2014;35:279-282.
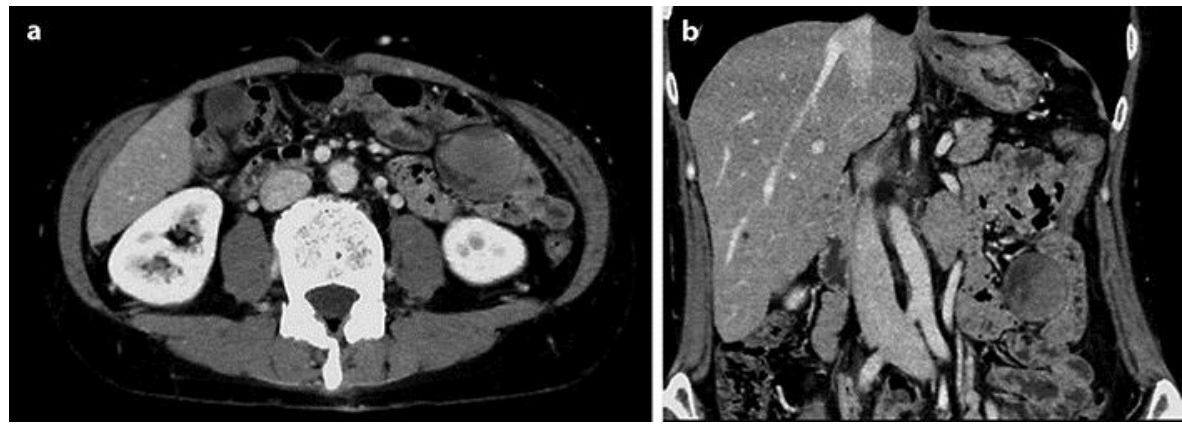

Fig. 1. Contrast-enhanced computed tomography in axial (a) and coronal (b) views showed a 4-cm-sized nonenhancing high-density mass with a heterogeneous pattern on a proximal small bowel loop. The mass was well separated from the neighboring vessels and organs. 

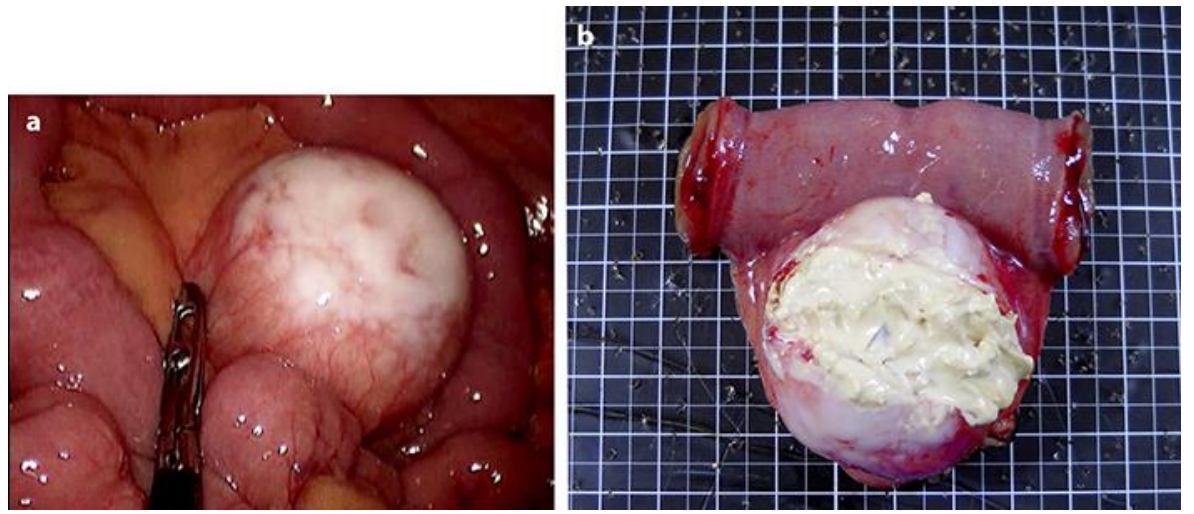

Fig. 2. a Exploration of the abdominal cavity identified a 4-cm mass originating from the mesentery of the jejunum. b Macroscopically, the mass appeared to be a cystic mass of the jejunal mesentery. The mass within the cyst lumen consisted of white clayish material.

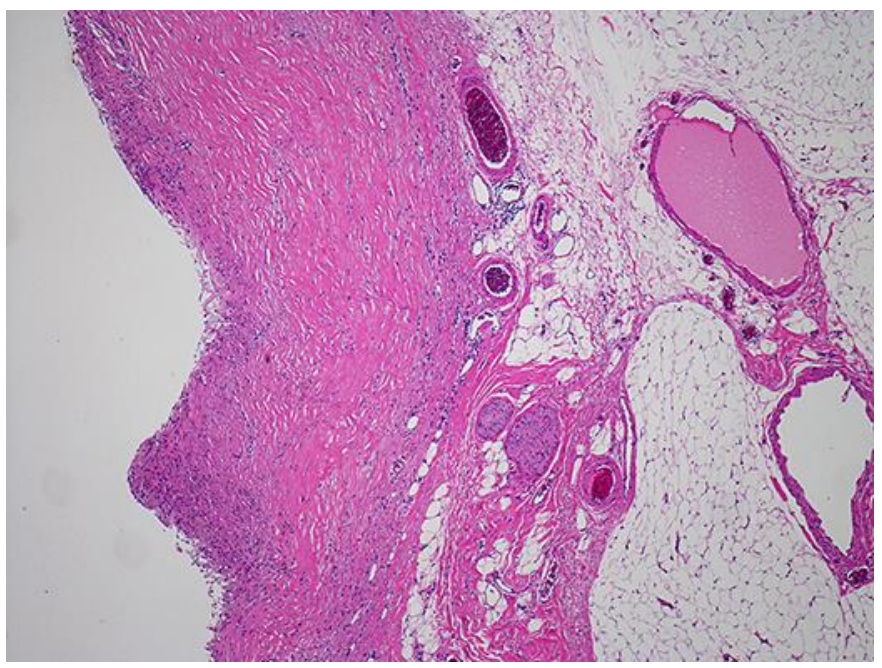

Fig. 3. Histopathological examination of the resected tissues showed that the cystic wall was made up of fibrous tissue with infiltration of inflammatory cells, but neither a specific endothelial lining nor a proliferating lining was found. HE. $\times 40$. 